\title{
Doğum Sonu Dönemde Yapılan Geleneksel Uygulamalar*
}

Traditional Practices Applied In Pospartum Period

Ayseren Çeviki, Sultan Alan ${ }^{\mathrm{ii}}$

'Yüksek Lisans Öğrencisi, Çukurova Üniversitesi Sağlık Bilimleri Fakültesi Ebelik Anabilim Dalı,

https://orcid.org/0000-0002-9648-1667

iiDoç.Dr. Çukurova Üniversitesi Sağlık Bilimleri Fakültesi Ebelik Anabilim Dalı,

https://orcid.org/0000-0002-5403-3778

\section{öz}

Geleneksel uygulamalara, sağlık alanında sıklıkla rastlanmaktadır. Özellikle doğum sonu dönemde lohusalara ve yenidoğanlara yönelik geleneksel uygulamalar, hastalık ve tehlikeleri önlemek amacıyla sıklıkla yapılmaktadır. Bu uygulamalar; âdetler, tören, dinsel ve büyüsel işlemlerden oluşmaktadır. Kültürümüzde lohusanın 40 gün süresince dinlenmesi, yalnız bırakılmaması oldukça önemlidir. Kadının beslenmesine, bakımına ve al basmasını önlemeye yönelik kültürel uygulamalar yapılmaktadır. Ayrıca, yenidoğanın beslenmesine, bakımına ilişkin uygulamalar ve bazı törensel uygulamalar da doğum sonu dönemde sıklıkla uygulanmaktadır.

Anahtar Kelimeler: Geleneksel Uygulamalar, Lohusa, Yenidoğan, Kültür

\section{ABSTRACT}

Traditional practices are frequently encountered in the field of health. Traditional practices, especially for postpartum puerperians and newborns, are frequently performed to prevent disease and dangers. these applications; customs, ceremonies, religious and magical operations. In our culture, it is very important that maternity rest for 40 days and not be left alone. Traditional practices are made that to provide care and to prevent from evil spirits, of women. In addition, the practices of feeding and care of the newborn and some ceremonial practices are frequently applied in the postpartum period.

Keywords: Traditional Practices, Puerperal, Newborn, Culture

\footnotetext{
*Lokman Hekim Dergisi, 2020; 10 (1): 14-22

DOI: $10.31020 /$ mutftd.624508

e-ISSN: 1309-8004

Geliş Tarihi-Received:25 Eylül 2019 ; Kabul Tarihi - Accepted: 6 Kasım 2019

iletişim - Correspondence Author: Ayseren Çevik <ayseren01.cevik@gmail.com>
} 


\section{GíRiş}

Kültür, bir topluma ait olan gelenek, görenek ve alışkanlıkları kapsayan karmaşık bir bütün olarak tanımlanmaktadır. Gelenek ise, bir toplumda nesilden nesile aktarılan kültürel değerleri, alışkanlıkları ve davranışları içine alan bir kavramdır. Gelenekler, bireylerin yaşam stillerini etkilemektedir. Buna bağlı olarak kişilerin sağlık durumları da geleneklerden etkilenebilmektedir. ${ }^{1,2}$

Kadın sağlığını olumsuz yönde etkileyen en önemli sağlık sorunları gebelik, doğum ve doğum sonrası dönemlerde meydana gelmektedir. Bu dönemlerin sağlıklı geçirilmesi, sonraki dönemlerin de sağlıklı devam etmesine olanak sağlamaktadır. ${ }^{3}$

Modern tıp, teknolojik yenilikler ile gelişme göstermektedir. Ancak toplumda bu gelişmelere rağmen, sağlık hizmetlerinden yeterince yararlanamayan bireyler olabilmektedir. Sağlık hizmetine ulaşamayan bu kişiler, çözümü genellikle kültürel uygulamalarda aramaktadır. Geleneksel inanç ve uygulamalar dünyanın çoğu yerinde tedavi etme amacıyla yapılmaktadır. Bu uygulamalar, aynı toplum içinde; bölge, yöre, aile ve kişilere göre farklılıklar gösterebilmektedir. Kadının en hassas olduğu evlilik, doğum, doğum sonrası dönemlerde gelenek ve görenekler yoğun bir şekilde yaşanmaktadır. Bu gelenekler; kadın ve yeni doğmuş bebeğinin başına gelebilecek hastalık ve tehlikeleri önlemek amacıyla yapılmaktadır. Doğum sonu dönemde yapılan kültürel uygulamalar; âdetler, törenler, dinsel ve büyüsel uygulamalardan oluşmaktadır. ${ }^{5,6}$

Geleneksel sağlık uygulamalarının bazıları akılcı uygulamalar olsa da, bazıları sağlığa zarar verebilen ve yaşam kalitesini olumsuz yönde etkileyebilen veya sağlık üzerinde herhangi bir etkisi bulunmayan uygulamalardır. ${ }^{4}$

\section{DOĞUM SONU DÖNEM VE GELENEKSEL UYGULAMALAR}

\section{Kültür, Gelenekler, Değerler, İnançlar ve Tutumlar}

Nesilden nesile aktarılan değerler, tutumlar ve anlamlar bütününden oluşan kültür, değerler sisteminden ve birbirini bütünleyen çeşitli unsurlardan oluşmaktadır. Kültür, belirli bir gruba özgüdür ve sonradan öğrenilmektedir. ${ }^{7}$

Bireyler ile toplum arasında sıkı bir ilişki bulunmaktadır. İnsan, doğup büyüdüğg̈ topluma göre şekillenmektedir. Kültürün temelini de gelenekler oluşturmaktadır. ${ }^{8}$ Gelenekler; geçmiş-bugün-yarın üçgeninde gezinen ruh şeklinde tanımlanmaktadır. ${ }^{9}$ Görenek ise; bir uygulamayı görüldüğü gibi yapma alışkanlı̆̆ıdır. ${ }^{11}$ Bir diğer önemli kavram ise değerlerdir. Değerler; insan davranışlarına rehberlik eden kurallar şeklinde tanımlanmaktadır. Hangi davranışın iyi hangisinin doğru olduğunu belirten ölçütler veya fikirlerdir. ${ }^{11} \mathrm{Bu}$ ölçütlerde tutum da etkili olabilmektedir. Tutum, herhangi bir durumla ilgili düzenli ve devamlı inanç, duygu ve eylemler olarak tanımlanmaktadır. Insanlar, çevresel olayları inanç ve tutumları ile değerlendirmektedir. İnançların ortaya çıkışında; gözlemler, deneyimler, duygular, zekâ ve sosyal yaşam gibi faktörler etkili olmaktadır. Bu etkilenmeler sonucunda da bireyler doğru veya yanlış olarak kabul edilen inançlara sahip olmaktadır. ${ }^{11}$

\section{Geleneksel Uygulamalar ve Sağlık}

Geleneksel uygulamalara her alanda olduğu gibi sağlık alanında da rastlanmaktadır. Sağlık alanında yapılan geleneksel uygulamalar; toplumun değerleri, inançları ve kültürüne göre şekillenmektedir. Dünya Sağılı Örgütü geleneksel tıpı; sağlı̆ın sürekliliğini sağlama, geliştirme ve tedavi etme amacıyla yapılan farklı kültürel uygulamaların tamamı olarak tanımlamaktadır. ${ }^{11,31}$

Bazı sebeplerden dolayı sağlık hizmetlerinden faydalanamayan veya sağlık kuruluşuna gitmek istemeyen kişiler, çözümü geleneksel uygulamalarda arayabilmektedir. Gelenek ve görenekler, bazı dönemlerde daha yoğun yaşanmaktadır. Bu dönemler halk kültüründe, geçiş dönemleri (evlilik, doğum ve doğum sonrası dönem vb. gibi) olarak tanımlanmaktadır. Özellikle de doğum sonu dönemde lohusalara ve yenidoğanlara yönelik uygulamalar sıklıkla yapılmaktadır. Bu uygulamalar genellikle, anne ve bebeği hastalıklardan ve tehlikelerden korumak amacıyla yapılan önlemler niteliğinde birtakım âdetler, tören, dinsel ve büyüsel işlemler içermektedir. ${ }^{5,6,11,14}$ 


\section{DOĞUM SONU DÖNEMDE LOHUSAYA YAPILAN GELENEKSEL UYGULAMALAR}

\section{Lohusalık Dönemi}

Doğumdan sonraki ilk 24 saatten sonra başlayıp, 7-10. güne kadar devam eden dönem "erken postpartum evre" ve bundan sonraki 6-8 haftalık süreç ise "geç postpartum evre" olarak tanımlanmaktadır. Bu dönemdeki kadına ise "Iohusa" adı verilmektedir. Postpartum dönemde kadınlar, fizyolojik ve psikolojik değişimler yaşamaktadır. ${ }^{10} \mathrm{Bu}$ değişimler, kadının yaşam kalitesini ve dolayısıyla da sağlığını etkilemektedir. Bu dönemlerin sağlıklı geçirilmesi, sonraki dönemlerin de sağlıklı devam etmesine olanak sağlamaktadır. ${ }^{3}$ Doğum sonu dönemde sosyal destek, bu dönemin sağlıklı bir şekilde geçirilebilmesine yardımcı olabilmektedir. Doğum sonrası dönemde; anne ve bebeğin sağıı̆ını sürdürmek, geliştirmek ve sosyal destek temel hedefler olarak görülmektedir. ${ }^{12}$ Postpartum dönem ebelik ve hemşirelik bakımı doğumdan hemen sonra başlanmalı ve lohusanın ihtiyacı olan eğitimler verilerek taburcu edilmesi sağlanmalıdır. ${ }^{13}$ Postpartum dönem, anne ve bebeğin bakıma ihtiyaç duyduğu bir dönemdir. Bu dönemde verilecek bakım; anne, yenidoğan ve ailenin ihtiyaçlarını karşılamaya odaklanmalı ve bu doğrultuda düzenlenmelidir. ${ }^{11}$

\section{Türkiye'de Doğum Sonunda Lohusaya Yapılan Geleneksel Uygulamalar}

Doğum yapan ve taburcu olup eve gelen kadına yapılan ilk şey yatak hazırlamaktır. Bu yatak kırmızı renkli ve süslüdür. Kırmızı renk kullanılmasının sebebi, al karısını korkutmak ve al basmasını önlemektedir. Lohusa kadın, en az üç gün süresince hazırlanan bu yatakta istirahat etmektedir. ${ }^{11}$

Toplumda, lohusalık döneminde beslenmenin önemli bir yeri bulunmaktadır. Bu dönemde lohusaya; enerji veren ve sütünü artıracak besinler verilmektedir. Lohusa kadının sıcak tutulmasına özen gösterilmektedir. Yeni doğum yapmış bir kadın toplumun her kesiminde ilgi ve saygı görmektedir. Yapılan kültürel uygulamalar da bu durumu destekler niteliktedir. ${ }^{11}$

\section{Al basmasına Yönelik Lohusaya Yapılan Geleneksel Uygulamalar}

Anadolu'da halk arasında "Al karısı" (Al basması/kırk basması) inancı çok yaygındır. Al karısının lohusa kadınlara görünerek onların korkmalarına, hastalanmalarına, ölmelerine neden olduğu ve bebeklerine zarar verdiği düşünülmektedir. ${ }^{11} \mathrm{Al}$ basmasına yönelik lohusaya yapılan uygulamalar iki kııımda ele alınmaktadır. Al basması gelişimini önlemek için yapılan uygulamalar ve al basmasını deneyimlediği düşünülen kadına yapılan uygulamalar şeklindedir. Bu uygulamalar Türkiye'nin tüm bölgelerinde benzerlik göstermektedir. ${ }^{11,14}$

\section{Al basmasını/kırk basmasını önlemek için lohusaya yapılan geleneksel uygulamalar:}

- "Lohusa ve bebeği odada tek bırakılmaz"

- "Lohusa karanlıkta yalnız bırakılmaz. Lohusa kadının odasındaki ışık söndürülmez"

- "Lohusa tekin olmayan yerlere (odunluk gibi) girmez"

- "Lohusanın başının altına ekmek, Kur'an, demir veya bıçak koyulur"

- "Lohusanın aynaya bakması ve saçını kestirmesi pek istenmez"

- "iki lohusa kadın birbirini ziyarete gitmez"

- “iki lohusa kadın yan yana gelince kırk karışmasını önlemek için iğne değiştirir veya birbirlerinin birer düğmesini kopartıp saklar"

- "Yeni doğum yapmış iki anne, yenidoğan ve babaları aynı ortamda bulunursa, kırk karışmasını önlemek için, bir miktar bozuk parayı aralarında değişirler (arılık değiştirme)."

- "Lohusa kadının yanına adetli kadın girmez"

- "Lohusanın yanına yeni gelin alınmaz"

- "Lohusa kadının bulunduğu evde erkek olur veya bir erkeğin eşyası bulundurulur"

- "Evden tuz verilmez, eve hayvan girdirilmez" 
- “Lohusa kadına kırmızı tülbent, kırmızı kurdele bağlanır"

- "Lohusa kadına yeşil bir örtü örtülür"

- "Lohusanın yatağı kırmızı ve siyah iple çevrilir"

- "Gelenlere kırmızı şerbet ikram edilir"

- "Lohusanın yanına su ve ekmek konur"

- Bir günde iki kırklı kadını ziyarete gidilmez. Düğün evinden, ölü evinden çıkan kimse lohusa ziyaretine gidemez"

- Kırklı kadın değirmene, fırına, düğüne gidemez ve eşikten atlayamaz.

- "Eve yeni bir şey geldiğinde lohusanın -o seni basmadan sen onu bas- diyerek yere ayağıyla bir şey ezer gibi basması istenir"

- "Kapının arkasına orak ucuna takıımış soğan veya sarımsak asııır". ${ }^{11,14,16-20,30}$

\section{Al basması/kırk basması oldu ise yapılan uygulamalar:}

- "Anne ve bebeğin yedi çeşmeden su getirilerek yıkanır"

- "Lohusanın yatağına arpa koyulur"

- "Lohusaya sigara ve alkol koklattırılır"

- "Lohusaya iğne batırılır"

- "Lohusaya tokat atılır"

- "Lohusaya kurşun döktürülür"

- "Lohusa hocaya okutulur"

- "Lohusanın elbisesinden parça alınıp tütsü yapılır"

- "Lohusanın evinin bacasına taş atıır".14,16,30

\section{Lohusanın Beslenmesine Yönelik Yapılan Uygulamalar}

- "Lohusaya, canı çekmesin diye gördüğü her şey yedirilir"

- "Lohusaya doğumdan sonra soğuk su ve pişmemiş gıdalar verilmez"

- "Yedi çeşit baharatın kaynatılmasıyla elde edilen kaynar içeceği, lohusaya ve ziyarete gelen misafirlere ikram edilir"

- "Lohusanın sütünün artması için su, süt, tatlı, incir, soğan, bulgur pilavı, pekmez, helva, şerbet, çorba, ciğer, et, melengiç, mercimek, börülce, meyve/meyve suyu, rezene çayı, sebze/salata, tereyağında eritilmiş pekmez yedirilir"

- “Sık aralıklarla emzirmek, lohusanın sütünü artırır".

\section{Lohusanın Bakımına Yönelik Yapılan Diğer Uygulamalar}

- "Lohusanın yere oturmasına izin verilmez"

- "Lohusa kadın, sıcak tutulması için höllüğe yatırıır"

- "Lohusanın kırk gün cinsel ilişkiye girmesi yasaklanır"

- "Lohusa cinsel ilişki sonrasında, dini abdest olmadan bebeğini emziremez"

- "Lohusa dua ve ibadet için camiye gidemez" 
- "Kanaması çok olan lohusanın altına kiremit ısıtıp konulur veya karnına bastırılır. Isıtılmış tuğla/toprak ile lohusanın karnı sarııı"

- "Dikişli doğumu (epizyotomi) olan kadınlar, yaralarının daha çabuk iyileşmesi için temiz bir bezin arasına yağda kızarmış yumurta koyulur ve cinsel organının üzerine yerleştirilir"

- "Doğum sonu ağrısı çeken lohusanın kaçıncı çocuğuysa o kadar gün acı çekmesi gerektiğine inanılarak ağrı kesici verilmez"

- "Meme başı çatlağı için zeytinyağı sürülür. Meme başlarına soğan sürmek çatlak oluşumunu önler"

- Lohusanın sütünü artırmak için kadının sağdığı süt, ergenlik çağına gelmemiş bir çocuğa verilir ve bu sütü incir ağacının dibine dökmesi istenir. Çocuk sütü, 'Incir gibi sütlü olsun' diyerek ağacın dibine döker"

- "Lohusayı korkutmamak ve sütünün çekilmesini önlemek için, yanında yüksek sesle konuşulmaz." $4,11,14,16,17$

\section{Diğer Ülkelerde Lohusaya Yapılan Geleneksel Uygulamalar}

- Hindistan'da anne ve bebeğin doğumdan sonra savunmasız olduğu kabul edilir. Birçok bölgede, doğum sonrasında evde kalma süresi 40 güne kadar uzayabilir. Bu sınırlandırma, anne ve bebeği hastalığa maruz kalmaktan ve kötü ruhlardan korumak için uygulanmaktadır. Doğum sonrası uygulamalar genellikle anneler, teyzeler ve diğer yaşlı kadın akrabalar tarafından uygulanır. ${ }^{19}$ Taylandlı kadınlar, aile üyeleri ve kocaları tarafından desteklenerek yaklaşık 30 gün boyunca evde dinlenmektedir. Meksikalı kadınlar ise doğum sonrası ortalama 40 günlük süreci evde dinlenerek geçirmektedir. ${ }^{21}$

- Tanzanya'da doğumdan sonra kadınlar, 6 ay boyunca kayınvalidelerinin evinde yaşarlar. Çünkü "doğumdan 6 ay sonra tekrar gebe kalırsa, bebek anne tarafından yeterince beslenemez, güçsüzleşir ve ölür" inancı vardır. ${ }^{22}$

- Meksika, Tayland, Hindistan, Kamboçya ve birçok bölgede lohusanın soğuktan kaçınmasına, sıcak tutulmasına, dinlenmesine özen gösterilir. Bu bölgelerde sıcak oturma banyoları yara iyileşmesini hızlandırmak için sıklıkla yapılır. Kadınlar gaz yapan bakliyat, yeşil yapraklı sebzeler, biber ve baharat alımından kaçınırlar. ${ }^{21,23}$

- Tayland, Vietnam, Kamboçya, Meksika, Nijerya, Guatemala ve Hmong gibi bölgelerde uterusun (rahimin) toparlanmasına yardımcı olmak ve perineal yara iyileşmesini hızlandırmak için sıcak kompres, sıcak tuzlu su çözeltisine oturma, karnın bağlanması gibi yöntemler uygulanır. ${ }^{21,24}$

- Hindistan'daki anneler arasında süt, fındık gibi yiyeceklerin dengeyi yeniden kazanmaya yardımcı olduğu düşünülmektedir. Kore'de, kahverengi deniz yosunu ve et suyu doğum sonrası kadının vücudunu temizlemek ve anne sütünü arttırmak için kullanılır. Hazımsızlık ve ishalin önlenmesi için, pirinç gibi yiyecekler, ikinci veya üçüncü güne kadar tüketilemez. ${ }^{21}$

- Nijerya'da lohusa emzirmeyi uyarmak için çeşitli alkollü içecekler (Hurma şarabı gibi) tüketebilmektedir. ${ }^{24}$ Kolostrumu çevreleyen inançlardan dolayı, bazı kültürlerde emzirme gecikebilmektedir. Güney Asya'daki kadınlar kolostrumun sindirilemediğini düşünür ve bebeğe vermezler. Hindistan'daki kadınlar emzirmeye başlamak için 2 gün beklerler. ${ }^{21}$

- Birçok kültürde, doğum sonrası kadınlar kirlenmiş olarak görülmektedir ve bu nedenle özel hijyen uygulamaları gerekmektedir. Ürdünlü anneler, cinsel organlarını sabun ve suyla iyice yıkarlar, çünkü doğum sırasında kadının geçici olarak kirletildiğini düşünürler. Bazı kültürlerde (ör; Arap ülkeleri, Tayland ve Çin) kadınların doğum sonrası dinlenme süresi tamamlanana veya kanama kesilinceye kadar kirli olduğu kabul edilir. Bundan önce, kadınların genellikle cinsel ilişki kurmaları yasaklanır. Hmong kadınları için, doğum kanına temas eden herhangi bir materyal, evde yıkanmalı ve anne veya bebeğe zarar verebilecek ruhların dikkatini çekmemesi için toprağa gömülmelidir. ${ }^{21}$ 


\section{Yapılan Geleneksel Uygulamaların Lohusa Kadının Sağlığı Üzerine Etkisi}

Doğum sonu dönemde lohusaya yapılan uygulamalardan bazıları sağlık üzerinde herhangi olumsuz bir etki oluşturmazken, bazıları sağlığı olumsuz yönde etkileyebilmektedir. Lohusa kadını yalnız bırakmama, sosyal destek sağlama, dinlenmesini destekleme, süt oluşumu artırmak için enerji veren gıdalar yedirme, gaz yapan gıdalardan kaçınma, kadını soğuktan koruma - sıcak tutma, memeye sıcak havlu uygulama, kırk gün cinsel ilişkide bulunmama, bebeği sık sık emzirme gibi uygulamalar kadının sağlığı üzerine olumlu etkiler oluşturabilmektedir. Ancak; emzirmenin geciktirilmesi, karnı sarma, karın üzerine sıcak kiremit koyma, kadının doğum sonrası dönemde kirlenmiş kabul edilerek genital bölgesinin sabunla yıkanması gibi uygulamalar kadının sağ|ı̆̆ı üzerinde olumsuz etkiler oluşturabilmektedir.

\section{DOĞUM SONU DÖNEMDE YENIDOĞANA YAPILAN GELENEKSEL UYGULAMALAR}

\section{Yenidoğan Dönemi}

Yenidoğan dönemi, bebeğin doğumdan sonraki ilk dört haftayı (ilk 28 gün) kapsamaktadır. Bu dönemdeki bebeklere ise "yenidoğan" adı verilmektedir. Çocukluk döneminin en yüksek ölüm oranına sahip dönemdir. Bu dönemde, sağlık kontrollerinin ve evde bakımın sağlanması, aile bireylerinin yenidoğan bakımı hakkında bilgilendirilmesi önemlidir. ${ }^{25}$

\section{Türkiye'de Doğum Sonu Dönemde Yenidoğana Yapılan Geleneksel Uygulamalar}

Yenidoğan, doğduktan hemen sonra fonksiyonel olmayan inanç ve uygulamalara maruz kalmaktadır. Bu dönemde; yenidoğanın beslenmesine, hijyen ve bakımına, sarılık olma durumuna yönelik geleneksel uygulamalar ve törensel uygulamalar yapılmaktadır. ${ }^{14}$

\section{Yenidoğanın Beslenmesine Yönelik Yapılan Uygulamalar}

- "Bebeği beslemek için 3 ezan beklenmelidir"

- "Bebek, kulağına ezan okunmadan beslenmeye başlamaz"

- "Bebeğe ağız sütü (kolostrum) verilmez"

- "Bebek doğduktan sonra ilk besin olarak şekerli su verilir"

- "Bebek tereyağı ve bal ile beslenmelidir".,411,14

\section{Yenidoğanın Bakımına Yönelik Yapılan Uygulamalar}

- "Bebeğin sarılık olmasını önlemek için yüzüne sarı yazma örtülür"

- "Bebek, kolları ve bacaklarının düzgün olması için kundaklanır"

- "Bebek, ter kokmasını ve isilik olmasını engellemek için tuzlanır"

- "Bebeğin tırnakları kırkı çıkana kadar kesilmez"

- "Bebeğin göbeğine zeytinyağı sürülür"

- "Bebek, üşümemesi için höllüğe yatırılır"

- "Bebeğin huysuzluk etmemesi ve iyi uyuması için ninni söylenir"

- "Bebekte pişik oluşmuşsa anne sütü, pudra veya zeytinyağı sürülür, bebek höllüğe yatırılır"

- "Pamukçuk oluştuğunda bebeğin ağzı karbonatla silinir"

- "Bebeğin sarı ve al basmasını önlemek için, ilk giydiği kıyafetlerde sarı ve kırmızı rengi bulunmalıdır"

- "Yeni kıyafet giyen bebek ilerde fakirlik çekmez. Bebeğin giydiği ilk kıyafet yeni olmalıdır"

- "Bebek yıkanırken -suyu artmasın, eti artsın- denilir".,11,14 


\section{Yenidoğanın Göbeğine Yönelik Yapılan Uygulamalar}

- “Bebeğin göbek bağı düştüğünde; dinine düşkün olması için cami avlusuna veya okuması için okul bahçesine gömülür"

- "Bebek, göbeğinin atıldığı yer ile ilgili bir mesleğe sahip olur"

- "Bebeğin göbeği saklanır"

- "Bebeğin göbeği üzerine madeni para veya taş koyulursa, göbek güzel olur"

- "Bilge kabul edilen birisi bebeğin göbeğine tükürür"

- "Göbek rutubetli bir yere atılırsa, bebek çabuk büyür".,11,14

\section{Yenidoğana Yapılan Törensel Uygulamalar}

- "Doğumdan sonra yedi gün içerisinde, bebeğin kulağına ezan okunur ve ismi konulur"

- “Tek sayılı günlerde (9., 11., 15. gün gibi) mevlit okutulur ve beşiğe yatırma töreni yapılır. Bebek beşiğe yatırıldıktan sonra beşiğin içine bahşiş atııı"

- "Lohusa ve bebeğin kırkı çıkarııır."

- Anne ve bebek 7, 20 ve 40. günlerde birlikte yıkanır. Doğumdan yirmi gün sonra, "yarı kırk çıkarma" yapılır. 20 tane küçük çakıl taşı, dua okunarak suyun içine atılır. Daha sonra anne ve bebek bu su ile yıkanır. Kırkıncı günde ise "kırk çıkarma" yapııı. Kırk banyosunda suyun içine 40 tane küçük taş, 40 buğday tanesi, 40 tane zeytin yaprağı, yumurta kabuğu, altın, gümüş, bozuk para, nazar boncuğu ve gül yaprağı gibi maddeler suyun içine eklenir. Daha sonra anne ve bebek bu su ile yıkanır.

- Mevlit okutulur.

- Kırk çıkarma gezmesine gidilir, akrabalar ziyaret edilir. Gidilen yerlerde bebeğe hediyeler verilir. ${ }^{11,14,18}$

\section{Yenidoğana Yapılan Diğer Uygulamalar}

- "Bebeğin tatlı dilli olması için ağzına bal sürülür"

- "Nazar değmesin diye bebeğe nazar boncuğu, ayet, cevşen, Kur’an takılır ve hocaya götürülür"

- Bebeğin bıngıldağının daha hızlı kapanması için zeytinyağı, badem yağı, yumurta karışımının ısıtıldıktan sonra kafasına sürülüp bir gün bekletilir."

- "Bebeğin gözüne limon damlatılırsa gözlerinin parlaklığı artar."

- "Antiseptik etkisi (mikrop öldürücü) olduğu düşünülerek sarımsak ve zeytinyağında bekletilen sürme, süpürge çöpü yardımıyla bebeğin göz kapaklarına çekilir." 4,11,14,29

\section{Diğer Ülkelerde Yenidoğana Yapılan Geleneksel Uygulamalar}

Hindistan'da çoğu kadın, yenidoğanların nazardan etkilendiğine inanırlar. ${ }^{23}$ Tanzanya'da doğumdan sonraki 6-7 gün boyunca (bebeğin göbek kordonu düşene kadar), kötü gözlerden dolayı bebek aile üyesi olmayan yabancı kişilere gösterilmez. Bebeğin göbek kordonu düşene kadar göbek kordonuna kimse dokunamaz. Bebek doğduğunda aile tarafından bir keçi (erkek bebek için erkek keçi ve dişi bebek için dişi veya erkek keçi) kesilir. Keçinin kulağından bir parça deri kesilir ve bebeğin alnına keçi derisinden kanla bir haç yapııır. Bebek hastanede doğmuşsa, bu tören bebek eve girmeden önce yapılır. Kesilen keçinin sakatatları ve bağırsakları bir muz ağacının dibine bırakııır. ${ }^{22}$

\section{Yapılan Geleneksel Uygulamaların Yenidoğan Sağlığı Üzerine Etkisi}

Doğum sonu dönemde yenidoğana yapılan uygulamalardan bazıları bebeğin sağlığı üzerinde herhangi olumsuz bir etki oluşturmazken, bazıları sağlığını olumsuz yönde etkileyebilmektedir. Bebeğe şekerli su, bal vb. gibi gıdaların verilmesi, kundaklanması, tuzlanması, göbeğine yabancı para gibi yabancı cisimlerin 
koyulması, emzirilmesinin geciktirilmesi, ilk sütün verilmemesi vb. gibi uygulamalar yenidoğan sağlığı üzerinde olumsuz etki oluşturabilmektedir. Ancak; yenidoğanın yabancılardan uzak tutulması, yalnız bırakılmaması, annesinin yanında olması, ninni söylenmesi gibi uygulamalar bebek sağı̆̆̆ı üzerine olumlu etkiler oluşturabilmektedir. ${ }^{4,11,14,22}$

\section{SONUÇ VE ÖNERILER}

Kültürel özellikleri dışlayan bir sağlık bakım hizmeti toplum tarafından yok sayılabilmektedir. ${ }^{28} \mathrm{Bu}$ aşamada sağlık profesyonellerine önemli görevler düşmektedir. Bu görevlerden ilki; toplumu bazı geleneksel uygulamaların sakıncaları hakkında bilgilendirmek ve yeni olanakların sunduğu imkanları anlatmaktır. íkinci görev ise, gebelik, doğum ve doğum sonrası izlemde kişilerin geleneksel uygulamalara yönelerek zarar görmesini önlemektir. Çünkü geleneksel uygulamalara yönelme, genellikle çağdaş sağlık anlayışı ve tıbbın sunduğu imkanlardan haberi olmayan kişilerde görülmektedir. Bu durum, kişilerin kültürlerini yargılayıp tamamen yok saymadan, bilgilendirme yoluyla düzeltilebilmektedir. ${ }^{17}$

Sonuç olarak; doğum sonu dönemde ebeler ve hemşireler, ailelerin inanç ve kültürel uygulamalarının farkında olmalı, sağlık üzerinde olumsuz etkisi olmayan uygulamaları desteklemeli ve olumsuz etkisi olan uygulamaları bilgilendirme yoluyla en aza indirmelidir. Ayrıca; geleneksel uygulamaların anne ve yenidoğan sağlığı üzerine olan etkisini inceleyen çalışmaların yapılması önerilmektedir.

BiLGi

Çalışmanın bir bölümü, 18-21 Haziran tarihlerinde Kırşehir'de gerçekleştirilen XI. Lokman Hekim Tıp Tarihi ve Folklorik Tıp Günleri'nde "Al Basmasına Yönelik Lohusaya Yapılan Geleneksel Uygulamaların İncelenmesi" başlığı altında poster bildiri olarak sunulmuştur.

\section{KAYNAKLAR}

1. Başal HA. Türkiye'de doğum öncesi ve doğum sonrası çocuk gelişimi ve eğitimine ilişkin gelenek, görenek ve inançlar. Uludağ Üniversitesi Eğitim Fakültesi Dergisi. 2006;19(1):45-70.

2. Arısoy A, Canbulat N, Ayhan F. Karaman ilindeki annelerin bebeklerinin bakımında uyguladıkları geleneksel yöntemler. Anadolu Hemşirelik ve Sağlık Bilimleri Dergisi. 2014;17(1):23-31

3. Taşkın L. Doğum ve kadın sağlığı hemşireliği. 12. Baskı. Akademisyen Tıp Kitabevi; 2014.

4. Çetişli NE, ve ark. Ege bölgesinde doğum sonu dönemde uygulanan geleneksel uygulamlar. Uluslararası Hakemli Hemşirelik Araştırmaları Dergisi. 2014;1:22-35.

5. Coşkun A, ve ark. 0-1 yaş bebeği olan annelerin bebek bakımında kullandıkları geleneksel yöntemlerin incelenmesi. IV. Ulusal Hemşirelik Öğrencileri Kongresi Kongre Kitabı;2005;12.

6. Cengizhan SÖ. Doğumlardan Sonra İlk 24 Saatte Bebek ve Loğusa Bakımında Kültürel Uygulamalar. Yüksek Lisans Bitirme Projesi, İnönü Üniversitesi Sağlık Bilimleri Enstitüsü, Malatya, 2014.

7. Yeşil S. Kültür ve kültürel farklııklar: liderlik açısından teorik bir değerlendirme. Elektronik Sosyal Bilimler Dergisi. 2013;12(44):5281.

8. Dikici A. Geleneklerin toplumdaki yeri ve önemi. Fırat Üniversitesi Sosyal Bilimler Dergisi. 2001;11(2):251-258.

9. Karadeniz S. Gelenek üzerine bir okuma denemesi "geçmişle gelecek arasında gelenek”. Milel Ve Nihal: İnanç, Kültür Ve Mitoloji Araştırmaları Dergisi. 2007;4(2):29-47.

10. Bal MD, Yılmaz SD. Ebelere Yönelik Kapsamlı Doğum. 1.Baskı. Akademisyen Tıp Kitabevi;2017.

11. Yalçın H. Anne Adaylarına Verilen Eğitimin (ASBEP) Gebelik, Doğum, Lohusalık Ve Bebek Bakımına İlişkin Fonksiyonel Olmayan Uygulamalara Etkisi (Karaman ili Örneği). Doktora Tezi, Selçuk Üniversitesi Sosyal Bilimler Enstitüsü Çocuk Gelişimi ve Eğitimi Bilim Dalı, Konya, 2011.

12. WHO. Technical Consultation on Postpartum and Postnatal Care. 2010.

13. Güneri SE. Postpartum erken dönem kanıta dayalı uygulamalar. Gümüşhane Üniversitesi Sağlık Bilimleri Dergisi. 2013;4(3):482496.

14. Akman G, Gözüyeşil E. Doğum sonu dönemde geleneksel uygulamalar yönelik yapılan araştırmaların incelenmesi. Uluslararası Hakemli Kadın Hastalıkları ve Anne Çocuk Sağı̆̆̆ Dergisi. 2018;12.

15. Esencan TY, Şimşek Ç. Doğum sonu dönemde hemşirelik bakımı. Zeynep Kamil Tıp Bülteni. 2017;48(4):183-189. 
16. Gölbaşı Z, Eğri G. Doğum sonu dönemde annenin bakımına yönelik yapılan geleneksel uygulamalar. Cumhuriyet Tıp Dergisi. 2010;32:276-282.

17. Işık MT, Akçınar M, Kadıoğlu S. Mersin ilinde gebelik, doğum ve loğusalık dönemlerinde anneye ve yenidoğana yönelik geleneksel uygulamalar. Uluslararası İnsan Bilimleri Dergisi. 2010;7:1.

18. Koyun A, ve ark. Kadınların gebelik, doğum yenidoğan bakımına ilişkin geleneksel inanç ve uygulamaları. Aile ve Toplum EğitimKültür ve Araştırma Dergisi. 2010;11:6.

19. Healt.qld.gov [internet]. Cultural dimensions of pregnancy, birth and post-natal care - Indian. [2019 April 14]. Available from: https://www.health.qld.gov.au/_data/assets/pdf_file/0030/158781/indian-preg-prof.pdf

20. Altuntuğ K, Anık Y, Ege E. Traditional practices of mothers in the postpartum period: evidence from Turkey. African Journal of Reproductive Health. 2018;22(1):95.

21. Dennis CL, ve ark. Traditional postpartum practices and rituals: a qualitative systematic review. Women's Health. 2007;3(4):487502.

22. Ohnishi M, Oishi K, Leshabari S. Customs and practices during pregnancy, childbirth, and the postpartum period in the Kilimanjaro area, Tanzania. Health Science Research. 2015;27:85-90.

23. Bhuvaneswari BG, Swarna S. Cultural beliefs and practices among postnatal mothers in selected rural areas Tirupati. NNJ. 2015;4(3):44-46

24. Okeke TC, ve ark. Postpartum practices of parturient women in Enugu, South East Nigeria. Annals of Medical and Health Sciences Research. 2013;3:1.

25. Gabbe S, et al. Obstettrics. 7nd ed. Elsevier; 2017.

26. Altuntuğ K, Ege E. Sağlık eğitiminin annelerin taburculuğa hazır oluş, doğum sonu güçlük yaşama ve yaşam kalitesine etkisi. Turkish Journal of Research \& Development in Nursing. 2013;15(2).

27. Taşhan ST, Koyuncu SB. Kadınların doğuma yönelik kullandıkları geleneksel yöntemler ve etkileyen faktörler. ACU Sağlık Bilimleri Dergisi. 2018;9(2):150-155.

28. Alan S, et al. Traditional health practices in mountain, plain and seaside regions of Adana in Turkey. Indian Journal of Traditional Knowledge. 2012;11(4):593-601.

29. Alan S, ve ark. Kültürümüzde yer alan geleneksel sağlık uygulamalarına ilişkin bir çalışma. Çukurova Üniversitesi Sağlık Bilimleri Dergisi. 2009;25(1,2,3):137-147.

30. Bakır E, ve ark. Adana'da albasması inanışı ve geleneksel uygulamalar. Lokman Hekim Journal. 2011;1(1):13-18.

31. WHO [internet]. Traditional medicine. [2019 October 9]. Available from: https://www.afro.who.int/health-topics/traditionalmedicine 